\title{
JUAN JOSÉ DE PALAFOX, GOBERNADOR DE CARTAGENA (1750-1756). COMPLEJIDAD JURISDICCIONAL E IMPUNIDAD EN UN TERRITORIO MILITARIZADO
}

\author{
María Luisa Álvarez y CAÑas \\ Universidad de Alicante
}

Fecha de recepción: noviembre 2013

Fecha de aceptación: mayo 2014

El sistema de gobierno implantado por Felipe V, con la intención de procurar la centralización administrativa y el control político y social de la población, concedió un gran protagonismo a las elites del ejército borbónico. El proceso de militarización territorial española, a partir de la designación de miembros de la institución castrense en labores de gobierno, alcanzó especialmente a los territorios «rebeldes» de la Corona de Aragón, así como a las principales plazas de frontera y de guerra, entre las que se encontraba Cartagena, cuyas condiciones geoestratégicas les confería una notable entidad en el organigrama del Estado ${ }^{1}$.

En el siglo XVII la demarcación de Murcia conformaba un solo corregimiento, tradicionalmente de capa y espada, que incluía a Cartagena y Lorca, localidades donde el corregidor se encontraba representado por sendos alcaldes mayores ${ }^{2}$. En 1675 el

1. Giménez LóPez, E.: «El Régimen de Nueva Planta y el debate civilismo-militarismo en la España del siglo XVIII», en Ejército, Ciencia y Sociedad en la España del siglo XVIII, Instituto de Cultura «Juan Gil-Albert», Alicante, 1995, pp. 289-325; y Archivo General de Simancas (en adelante, A.G.S), Gracia y Justicia, Leg. 816: «Corona de Castilla».

2. Su territorio ocupaba un área de 16 leguas. Archivo General de Simancas (en adelante, A.G.S.), Catastro de Ensenada, Leg. 463, Cartagena, 18 de noviembre de 1755, fols. 353-376. Para conocer su evolución administrativa, Tornel Cobacho, C.: El gobierno de Cartagena en el Antiguo Régimen: 1245-1812, Concejalía de Cultura, Cartagena, 2001. 
extenso término de Lorca se escindió en un corregimiento independiente ${ }^{3}$, mientras que el de Cartagena nació en 1706, sin ningún otro pueblo sujeto a su jurisdicción ${ }^{4}$. La autoridad del corregidor se encontraba subordinada a otros organismos superiores: en materia política al Consejo de Castilla, en materia judicial a los dictámenes del Tribunal de la Chancillería de Granada, y respecto a las instancias militares obedecía las órdenes del Capitán General de Valencia, tal y como se estableció en 1714 a partir del reparto de oficiales generales para el mando de las provincias. En esa fecha se dividió el mando del reino de Valencia: el territorio comprendido desde el Júcar hasta el límite con Murcia correspondió al teniente general Lucas Spinola, mientras el reino de Murcia recayó en el teniente general marqués de Mirabel, con la calidad excepcional de comandante general y gobernador, pero siempre subordinado al Capitán General ${ }^{5}$.

Durante el siglo XVIII la designación de corregidores de toda índole se encontraba en manos del monarca. El procedimiento de selección de los gobernadores político-militares se tramitaba sobre todo a través de la vía reservada de la Secretaría del Despacho de Guerra, cuyo carácter ejecutivo permitía la rapidez de los nombramientos directos, soslayando la tradicional consulta de pretendientes para la provisión de cada corregimiento ${ }^{6}$.

Los corregidores de Cartagena se convirtieron en gobernadores con jurisdicción político-militar de forma estable a partir de 1722. La organización del mando militar y del puerto, volcada desde antiguo en la provisión de la flota real y de los presidios norteafricanos, se completó con la creación en 1726 del Departamento Marítimo de Cartagena bajo el mando de un teniente general de la Real Armada ${ }^{7}$. Para su gerencia se añadieron otros funcionarios encargados de su juzgado y administración, formando una estructura burocrática muy compleja que se incrementó a partir de 1731 con la instalación de un importante arsenal ${ }^{8}$.

La concurrencia de tan extenso número de agentes reales, a los que se sumaron los principales mandos de la Armada de su región dio lugar a numerosos conflictos de competencias, no sólo por la falta de entendimiento entre civiles y militares, sino también entre los distintos mandos castrenses.

3. Gómez Vizcaíno, A. y Munuera NaVArro, D.: «La fortificación del siglo XVIII», en Estudio y catalogación de las defensas de Cartagena y su bahía, 2004, pp. 172-237. http://www.arqueomurcia.com

4. Archivo Histórico Nacional (en adelante, A.H.N.), Consejos, Libro 723, fol. 88.

5. A ambos tenientes generales se les asignó junto a su nombramiento un sueldo de 375 escudos mensuales. A.G.S., Guerra Moderna, Libro 1852.

6. González Alonso, B.: El corregidor castellano. 1348-1808, Instituto de Estudios Administrativos, Madrid, 1970, p. 262.

7. Melendreras Gimeno, M. C.: Fortificación de la base naval de Cartagena en el siglo XVIII: proyectos, mapas y planos, Vol. 11, Editum, Murcia, 2009, pp. 17-20.

8. Roda Alcantud, C.: «La Base Naval de Levante: significado histórico del arsenal para la ciudad de Cartagena». Actas II Jornadas sobre Fortificaciones Modernas y Contemporáneas (1500-1936), Cartagena, Aglaya, 2001, pp. 309-315; MarZAL, A.: «Las fortificaciones de Cartagena en el siglo XVIII». R.H.M., $\mathrm{n}^{\circ}$ 41, Madrid, 1976, pp. 31-43. 
Las frecuentes rivalidades jurisdiccionales en el gobierno del Antiguo Régimen derivaron en una marcada conflictividad entre los distintos responsables de los fueros privilegiados ${ }^{9}$, cuya resolución se complicó por la supremacía militar fortalecida por los dictados de Felipe V tras la guerra de Sucesión y los Decretos de Nueva Planta.

\section{LOS INICIOS DEL GOBIERNO DE JUAN JOSÉ DE PALAFOX Y CENTURIÓN (1750-1756)}

Nacido en Madrid en 1674, y perteneciente a una familia de la aristocracia, era el segundogénito de Juan de Palafox y Rebolledo, Gran Almirante de Aragón y V marqués de Ariza $^{10}$, y de Francisca Paula Mexía y Centurión, marquesa de Almunia de la Guardia y condesa de Santa Eufemia. La tradicional dedicación a la carrera militar de los descendientes nobles sin título condujo a Juan José de Palafox a diversas actividades castrenses, sobre todo en Andalucía: en Málaga y Marbella ocupado en las tareas de provisión de los destacamentos destinados a los presidios menores; o en la movilización de reclutamientos en Granada. Además asumió el empleo de gobernador de la destacada plaza de Ceuta (1745-1746). La sintonía del mismo con las altas esferas de la Secretaria de Guerra ${ }^{11}$ favoreció su designación como gobernador político-militar de Cartagena, por decreto real del 16 de octubre de $1750^{12}$, cuando ya poseía el grado de mariscal de campo, al tiempo que recibió el nombramiento de caballero de la Orden de Santiago ${ }^{13}$.

Poco antes de su toma de posesión en el cargo ${ }^{14}$, las irregularidades registradas en el corregimiento de Cartagena habían merecido la atención del marqués de la Ensenada a propósito del cobro de derechos sobre las embarcaciones de comercio que transitaban por el puerto, cuestión que se enquistó largos años. Ante las quejas elevadas a la Secretaría de Guerra, se emitió una orden real dirigida tanto al intendente general de

9. Martínez Ruiz, E.: «Legislación y fuero militar», en Guerra y Sociedad en la monarquía hispánica: politica, estrategia y cultura en la Europa de la Edad Moderna, 1500-1700, vol. 1,CSIC, Madrid, 2006, pp. 11-32; GonzÁlez Alonso, B.: «La Justicia», en M. Artola (dir.), Enciclopedia de Historia de España, vol II, Alianza, Madrid, 1988; Maqueda Abreu, C.: Estado, Iglesia e Inquisición en Indias. Un permanente conflicto, Centro de Estudios Políticos y Constitucionales, Madrid, 2000, p. 36; LóPEz DíAz, M.: «Jurisdicción militar y jurisdicción ordinaria en el reino de Galicia. Conflictos y competencias a principios del siglo XVIII», en Anuario de Historia de Derecho Español, nº 81, 2011, pp. 679-708.

10. Con la distinción de Grande de España de primera clase. CÁdenAs y Vicent, V.: Extracto de los expedientes de la Orden de Carlos III (1771-1847), Tomo IX, Instituto Salazar y Castro (CSIC), Hidalguía, Madrid, 1986, pp. 205-206.

11. Andújar Castillo, F.: El sonido del dinero. Monarquía, ejército y venalidad en la España del siglo XVIII, Marcial Pons, Madrid, 2004, pp. 148-149.

12. Fue recibido en el empleo el día 12 de abril de 1751. A.G.S., Guerra Moderna, Leg. 1372: Antonio de Irusta al Exmo. Sr. marqués de la Ensenada, Cartagena, 14 de abril de 1751.

13. También era comendador de la Puebla de Sancho Pérez, en la comarca de Zafra (Badajoz). A.G.S., Gracia y Justicia, Leg. 151: San Lorenzo el Real, 16 de octubre de 1750; CADENAS Y Vicent, V.: Caballeros de la Orden de Santiago, siglo XVIII, Vol. 4, Hidalguía, Madrid, 1979, p. 54.

14. El 13 de abril de 1751. A.G.S., Guerra Moderna, Leg. 1.372: Real de Valencia, 20 de abril de 1751. 
Marina de Cartagena, Francisco Barrero Peláez, como a José de Contamina, intendente en Cataluña, para erradicar en dichos territorios el abuso cometido ${ }^{15}$.

La llegada de Palafox a Cartagena hizo ostensible el carácter prepotente de un militar que hacía prevalecer su autoridad, incluso a costa de las órdenes superiores de la jerarquía castrense a la que se encontraba sujeto. La circunscripción de Cartagena se hallaba entonces al mando del capitán general de Valencia duque de Caylus. Hombre de prestigio, la trayectoria de este oficial destacaba desde el año 1698, como brigadier de caballería en los Países Bajos, para desde entonces desempeñar su labor en diversos destinos al mando del ejército, y por su participación en la Guerra de Sucesión. Entre otros empleos, fue comandante general de la frontera de Extremadura (1715), de Aragón (1718-1721), capitán general de Galicia, y en 1737 fue designado para ocupar la capitanía general de Valencia. Incluso fue distinguido por Felipe V con el collar del Toisón de Oro, como Gentilhombre de Cámara, y en 1742 nombrado duque de Caylus, con grandeza de España de primera clase ${ }^{16}$.

Una vez reconocido el juramento de Palafox como nuevo gobernador por el duque de Caylus, éste le instruyó acerca de las fuerzas y el personal militar que se encontrarían en su distrito bajo sus órdenes y dispuestas para el real servicio. A parte de la guarnición propia de Cartagena, las tropas en tránsito eran: el Regimiento de Caballería de Santiago, emplazado en Lorca y Totana, y un escuadrón del Regimiento de Flandes, destinado en Murcia capital. Al mismo tiempo le indicó la cadena de mando habitual para el eficaz rendimiento de sus subalternos: las compañías alistadas para el resguardo de la costa y los alcaides de las torres debían informar primero al gobernador de cualquier contingencia, éste trasladar dichas novedades al comandante del Departamento de Marina, y mantener una comunicación semanal con el capitán general sobre lo acaecido. Asimismo, le notificaba las prioridades sobre la vigilancia de la costa contra las incursiones corsarias, y las precauciones sanitarias necesarias en el puerto para el resguardo de la salud ${ }^{17}$.

Sin embargo, en la primera ocasión Juan José de Palafox se desentendió de las órdenes del duque de Caylus. A pesar de las disposiciones dictadas por el capitán general para que el Regimiento de Santiago se movilizara hacia Cataluña y el escuadrón de Flandes hacia Andalucía, el gobernador se negó a obedecer la orden y recurrió al secretario del Despacho de Guerra para justificar su decisión ${ }^{18}$. Palafox había trasladado por su cuenta un destacamento de ochenta hombres pertenecientes al Regimiento de Santiago a los cuarteles inmediatos a la ciudad de Cartagena, con el fin de apostarlos al reguardo de la costa, disposición que no pensaba cambiar sin antes recibir las órde-

15. A.G.S., Guerra Moderna, Leg. 1.372: Copia de Real Orden, Madrid, 9 de febrero de 1751.

16. Sobre la figura del duque de Caylus, GimÉNez LóPEz, E.: Los servidores del rey en la Valencia del siglo XVIII, Institució Alfons el Magnànim, Valencia, 2006, pp. 309-310.

17. A.G.S., Guerra Moderna, Leg. 1.372: Real de Valencia, 20 de abril de 1751.

18. Estos traslados obedecían a las noticias comunicadas por el comandante general de Mallorca sobre el peligro del armamento de los argelinos. 
nes del marqués de la Ensenada ${ }^{19}$. Mantenía esta decisión bajo dos justificaciones: la primera, que antes debía recibir nuevas fuerzas en sustitución de las que debían partir por el riesgo en que quedaría el territorio sin las mismas, y la segunda, que todas las tropas de la plaza de Cartagena eran de su mando exclusivo, según entendía por el encargo anterior del duque de Caylus. Palafox alegaba que se sentía menospreciado ante la reconvención que mereció del capitán general, que debería además trasladarle las órdenes personalmente, y no a través de un corone ${ }^{20}$.

Por el contrario, el capitán general escribía a Ensenada criticando la actitud del gobernador, a quien reprochaba que ignorara «el artículo más esencial del servicio, que es la subordinación», entorpeciendo la urgente marcha del Regimiento de Santiago, con la equivocada idea de considerarse comandante general del reino de Murcia, grado que no le correspondía ${ }^{21}$. Finalmente, la discordia se zanjó con una real orden que afianzaba la subordinación debida, junto a una amonestación que prohibía a Palafox utilizar el título de comandante general, empleo que no le correspondía pues tanto las armas de la provincia de Valencia como las de Murcia se encontraban bajo la potestad de Caylus $^{22}$. El teniente general marqués de Villadarias, entonces inspector general de caballería ${ }^{23}$, intervino informando que sólo en el año 1714 se otorgó el título de comandante general, cuando fue destinado el teniente general marqués de Miravel al reino de Murcia, pero siempre a las órdenes de la capitanía de esa región militar ${ }^{24}$. Los conflictos entre corregidores militares y capitanes generales fueron muy frecuentes durante el siglo XVIII, debido a la difícil colaboración de oficiales de alta graduación, de antigüedad y orígenes nobles similares en el ámbito de las obligaciones de la jefatura territorial ${ }^{25}$.

19. A.G.S., Guerra Moderna, Leg. 1.372: Juan José de Palafox a D. Carlos Colucio, coronel del Regimiento de Santiago, mayo de 1751.

20. A.G.S., Guerra Moderna, Leg. 1.372: Juan José de Palafox al Exmo. Sr. marqués de la Ensenada, 9 de junio de 1751.

21. Los capitanes generales acudían al resguardo de los dictámenes de la Secretaria de Guerra para la resolución de sus problemas. AndúJAR CASTILlo, F.: «Capitanes generales y capitanías generales en el siglo XVIII», en Revista de Historia Moderna, Anales de la Universidad de Alicante, no 22, 2004, pp. 291320; A.G.S., Guerra Moderna, Leg. 1.372: El duque de Caylus al Exmo. Sr. marqués de la Ensenada, 21 de junio de 1751.

22. A.G.S., Guerra Moderna, Leg. 1.372: A Caylus, 24 de julio de 1751.

23. Era hijo del primer Capitán General de Valencia (1713-1716) de la administración borbónica. GIMÉNEZ LóPEZ, E.: Los servidores del rey... Op. cit. pp. 554-556.

24. A.G.S., Guerra Moderna, Leg. 1.372: Marqués de Villadarias, Aranjuez, 1 de julio de 1751.

25. Álvarez y CaÑas, M. L.: «Las conflictivas relaciones entre los corregidores militares y los capitanes generales de la costa de Andalucía y de la costa de Granada en el siglo XVIII», Baetica. Estudios de Arte, Geografía e Historia, nº 33, 2011, pp. 253-281. 


\section{LAS RESPONSABILIDADES DE UN TERRITORIO MILITARIZADO}

Las especiales circunstancias de la plaza de Cartagena supusieron que recayeran en Juan José de Palafox varias responsabilidades anexas al servicio del ejército de España, la mayoría de ellas relacionadas con la atención a las necesidades de la tropa. En este sentido, la dificultad para alojar a las tropas de la guarnición, así como a las acantonadas o en tránsito a la espera de destino, fue una de las responsabilidades más apremiantes en las plazas de frontera, sobre todo porque concernían a la seguridad del Estado y a la vez repercutían con mayor incidencia entre la población civil, conforme a las pesadas cargas que con frecuencia se le impusieron ${ }^{26}$. Convertido en un problema cotidiano, la resolución de los inconvenientes suscitados para este servicio en Cartagena fue uno de los asuntos que preocuparon a Palafox desde su llegada al corregimiento, donde se encontró con multitud de expedientes pendientes. Esta cuestión se acrecentaba por el limitado recinto de su territorio, que carecía del número suficiente de casas y cuyo arrendamiento se encarecía como consecuencia del crecido aumento de población atraída por las oportunidades económicas del arsenal.

Con el fin de solventar dicho cometido Palafox ideó un plan para evitar las frecuentes discordias y perjuicios surgidos en el vecindario, que en realidad suponía un control personal y absoluto sobre las propiedades particulares. Su intervención consistía en que tanto los dueños de casas como los futuros inquilinos que pretendían habitarlas se lo comunicaran primero a él, al igual que hasta entonces lo habían hecho algunos oficiales y vecinos, en uso de la condición que le confería su jurisdicción sobre la ciudad, y tal vez por deferencia a su cargo. Su intención era eliminar las nocivas prácticas de subarriendos, así como de anticipación de pago de alquileres, que oscilaban desde medio hasta un año entero, con el objetivo de asegurarse una vivienda ${ }^{27}$. El gobernador del Consejo calificó la medida de abusiva, pues provocaría repetidos recursos, en tanto que privaba de libertad a los propietarios de las casas $^{28}$. De manera que el plan de Palafox fue rechazado ${ }^{29}$.

Tampoco tuvo éxito con su particular gestión sobre el abastecimiento de la harina para la fabricación de pan con destino al Ejército, según se desprende de la deficiente mediación entre el asentista de la Provisión de Víveres de las Tropas de España, Francisco de Mendinueta, y uno de los capitulares de Cartagena. En un memorial dirigido a Ensenada, Mendinueta reclamaba una solución ante la falta de firmeza de Palafox en el cumplimiento del abastecimiento y la notoria injerencia de los poderes locales. Para cumplir su cometido según la reglamentación, Mendinueta podía dispo-

26. Borreguero Beltrán, C.: «Los problemas del alojamiento militar en la España del siglo XVIII», en Ejército, Ciencia y Sociedad en la España del Antiguo Régimen, E. Balaguer y E. Giménez (Eds.), Instituto de Cultura «Juan Gil-Albert», Alicante, 1995, pp.111-131.

27. A.G.S., Guerra Moderna, Leg. 1372: Juan José de Palafox al Exmo. Sr. Marqués de la Ensenada, Cartagena, 18 de agosto de 1751.

28. A.G.S., Guerra Moderna, Leg. 1372: El Marqués de la Ensenada al Sr. Obispo Gobernador del Consejo, Buen Retiro, 23 de agosto de 1751.

29. A.G.S., Guerra Moderna, Leg. 1372: Obispo de Sigüenza, Madrid, 8 de septiembre de 1751. 
ner de todas las casas, hornos, molinos y almacenes de la Real Hacienda, incluidos los particulares, a cambio de un alquiler justo. Así se observó sin dificultades hasta que el regidor comisionado para la administración del Pósito ordenó a los molineros que sólo aceptaran procesar el trigo de la Alhóndiga para el abasto del común, y rechazaran el del ramo de Provisión. Palafox calculaba que para la asistencia a la tropa se necesitaba el suministro de diez molinos, de los treinta y seis que existían en la circunscripción de su mando; sin embargo, ante la oposición de los interesados el gobernador los redujo a $\operatorname{cinco}^{30}$. Por otro lado, los molineros reclamaban al despacho de la Provisión la seguridad de su empleo durante todo el año junto a una mejora de salarios.

El gobernador declaraba que ante «la oposición de la ciudad» tuvo por conveniente destinar cinco molinos mediante un sorteo entre los mejores y más cercanos a la plaza, pues calculaba que durante 24 horas a pleno rendimiento se podrían obtener de 90 a 100 fanegas de harina, cantidad suficiente para la despensa de las tropas. Era consciente de que la negativa de los interesados provenía de la merma en las ganancias del trabajo de la molienda en relación a la carestía de la vida, pues comparaban la época en que Cartagena albergaba dos tercios menos de habitantes, cuando el coste de bienes de consumo era barato aunque los jornales fueran más exiguos. Por último, Palafox se hacía único responsable de esas medidas, desmintiendo que las órdenes provinieran del regidor disidente. Finalmente, como resultado del litigio, se ordenó al gobernador que facilitara a Mendinueta los hornos y molinos que había solicitado desde un principio ${ }^{31}$.

En definitiva, desde el inicio de su mandato el carácter de Palafox manifestó su rebeldía a plegarse a las órdenes establecidas y a cumplir la obediencia debida hacia sus superiores, tanto civiles como militares. La asunción de ambos poderes en sus manos dio lugar a numerosos conflictos con la mayoría de las autoridades de Cartagena y al malestar general de la población, perjudicada por sus arbitrariedades y abuso de gobierno. No obstante, no siempre encontró el respaldo necesario de las instituciones superiores en su defensa sobre la jurisdicción real que le competía. Además, la deseable relación profesional entre los responsables de los tribunales de justicia instalados en Cartagena fue prácticamente nula y se vio envuelta en disputas casi permanentes.

\section{CONFLICTOS DE INTERESES ENTRE LA JURISDICCIÓN ORDINARIA Y LA DE MARINA}

A partir de los autos formados en 1755 por el gobernador Juan José de Palafox contra un soldado de Marina se inició un debate lastrado desde el principio por cuestiones ajenas a la justicia, y que revelaba el afán de preeminencia de las principales autoridades militares de cualquier arma establecidas en la plaza. El conflicto se inició tras una reyerta en la que el marino causó la muerte de un soldado y heridas a otros dos pertenecientes al Regimiento de Infantería de León. Palafox intentó ejercer las facul-

30. A.G.S., Guerra Moderna, Leg. 1372: Memorial de D. Francisco de Mendinueta, diciembre de 1751.

31. A.G.S., Guerra Moderna, Leg. 1.372: Juan José de Palafox al Exmo. Sr. Marqués de la Ensenada, Cartagena, 22 de diciembre de 1751. 
tades judiciales que le correspondían, según se establecía en los procesos de delitos de muerte por uso de armas prohibidas, y en virtud de sendas órdenes despachadas por el marqués de la Ensenada, también comunicadas a su antecesor el brigadier Juan Antonio Pando y Patiño por el capitán general de Cataluña. En esencia, la primera orden advertía sobre la prohibición de las armas a cualquier persona de toda clase y condición, cuyo conocimiento competía de forma privativa a la justicia ordinaria, con la inmediata pérdida del fuero privilegiado que poseyeran tanto los actores del delito como los testigos $^{32}$. La segunda incluía la restricción sobre los habituales cuchillos flamencos que utilizaban las gentes de mar en las embarcaciones, vedados a partir de entonces de su uso y posesión en tierra. Dicho mandato fue publicado en los principales puntos de la ciudad de Cartagena por el intendente general Francisco Barrero Peláez ${ }^{33}$.

Aunque las versiones sobre el origen del altercado y su desarrollo variaban en algunos detalles, la principal controversia se hallaba en el desenlace del mismo. El detenido, Diego Garzón Navarro, soldado de un batallón de Marina, fue desarmado por un cabo de Granaderos cuando se encontraba bajo el dintel de la Iglesia de San Agustín, en presencia del alférez de Artillería José Montes de Oca, quien había dado la voz de alarma sobre la tenencia del cuchillo flamenco. Una vez que Garzón entregó el arma, fue trasladado al cuartel de Marina en calidad de preso ${ }^{34}$.

Tras sustanciar el peritaje del arma, la visita al Real Hospital donde se hallaban las víctimas, y la toma de declaraciones, el gobernador reclamó a Montes de Oca su testimonio sobre los hechos; sin embargo, a pesar de su obligación de cooperar con la justicia ordinaria, este respondió: «que atento de no estar firmadas dichas reales órdenes del rey ni de su jefe superior, y poder ser supuestas, no podía obedecer lo que se mandaba por el Sr. gobernador» ${ }^{35}$. En realidad ambas órdenes eran una fiel reproducción de las leyes cursadas por Fernando VI, de manera que el oficial incurría en clara desobediencia a los decretos reales y a la autoridad que en derecho debía aplicarlas ${ }^{36}$. Ante la falta de colaboración del testigo, Palafox elevó una queja al secretario del Despacho de Guerra en la que manifestaba la respuesta «denigrativa a la real jurisdicción» y exigía una satisfacción que sirviera de escarmiento ${ }^{37}$. También dirigió un recurso al marqués de Spínola, comandante general de Marina, en solicitud de la entrega del

32. A.G.S., Guerra Moderna, Leg. 1.373: El Duque de Caylus al Sr. D. Juan Antonio Pando y Patiño, Real de Valencia, 26 de junio de 1748.

33. A.G.S., Guerra Moderna, Leg. 1.373: El Duque de Caylus al Sr. D. Juan Antonio Pando y Patiño, Real de Valencia, 11 de julio de 1748.

34. A.G.S., Guerra Moderna, Leg. 1.373: Comparecencia de Juan Bautista de Castro, Cartagena, 30 de enero de 1755 .

35. A.G.S., Guerra Moderna, Leg. 1.373: Comparecencia de D. José Montes de Oca, Cartagena, 4 de febrero de 1755 .

36. Novísima Recopilación, Libro XII, Título XIX, Ley XVI: «Absoluta prohibición de armas blancas, con derogación de todo fuero en el uso de ellas», p. 389

37. A.G.S., Guerra Moderna, Leg. 1.373: Juan José de Palafox al Exmo. Sr. D. Sebastián de Eslava, Cartagena, 5 de febrero de 1755. 
reo para su traslado y reclusión en la cárcel real, y su ascendiente para que Montes de Oca compareciera como testigo en el tribunal del gobernador ${ }^{38}$. El comandante general rechazó ambos extremos en razón a su superioridad y despreciando el espíritu de la ley. Spinola argumentaba que él era el jefe natural del homicida y su detención se había producido en lugar sagrado, circunstancia que anulaba esa diligencia, de manera que el gobernador no podía hacer valer su derecho jurisdiccional. En refuerzo de su argumento, Spínola interpretaba que si Palafox insistiera en la calidad privativa de su fuero se encontraría con que Garzón era imputable de dos delitos: el primero, de muerte y heridas, con una pena capital que correspondería al cuerpo de Marina sentenciar; y el segundo, de aprensión de arma prohibida, que sólo podría inspeccionar el gobernador. En definitiva, en una competencia de igual naturaleza entre dos jurisdicciones debía vencer la de mayor gravedad, es decir, la merecedora de pena capital que debía tramitar el juzgado de Marina ${ }^{39}$.

La contrariedad del gobernador se había incrementado cuando desde la Secretaría de Guerra le expresaron que no podría resultar cargo alguno contra Montes de Oca porque los subalternos no podían hacer declaraciones sin licencia de sus comandantes $^{40}$. A pesar de todo, el gobernador insistió sin éxito en que se sostuviese el desafuero recogido en la legislación, con el respaldo de dos causas anteriores: la primera contra un marinero matriculado que se extrajo de la Iglesia, encarceló y condenó a pena de muerte tras un homicidio con arma prohibida, sin que fuera reclamado por la jurisdicción de Marina; y la segunda, en similares circunstancias, con un preso que en esas fechas esperaba condena sin que tampoco se acogiera a su fuero ${ }^{41}$.

La falta de colaboración en la instrucción de delitos cometidos con armas prohibidas fue una constante que difícilmente encontró solución durante el siglo XVIII. A pesar de que la potestad en el encausamiento pertenecía a la jurisdicción ordinaria $\mathrm{y}$ a los correspondientes tribunales superiores de justicia, sin entrar en competencia otros fueros, los interesados solían buscar resquicios legales e ignorar las leyes con el propósito de hacer prevalecer en todo momento su privilegio. En ocasiones estas actitudes fueron apoyadas por el gobierno central, incluso mediante la modificación de la normativa que incumbía al ámbito de gobierno militar, como ocurrió con los reajustes que favorecieron e incrementaron los amplios poderes de los corregidores de Cádiz y Málaga. En la misma línea, aquellos procesos cuya substanciación correspondía en principio a las Chancillerías y Audiencias fueron vinculados a la potestad del Consejo de Guerra ${ }^{42}$.

Las discriminaciones sufridas respecto a la autoridad de Palafox en Cartagena sin duda le causaron un grave malestar. No obstante, el gobernador había procedido con

38. A.G.S., Guerra Moderna, Leg. 1.373: Auto, Cartagena, 8 de febrero de 1755.

39. A.G.S., Guerra Moderna, Leg. 1.373: Exmo. Sr. marqués de Spinola, Cartagena, 12 de febrero de 1755. 40. A.G.S., Guerra Moderna, Leg. 1.373: D. Joaquín de Palafox. Cartagena, 8 de febrero de 1755.

41. A.G.S., Guerra Moderna, Leg. 1.373: D. Joaquín de Palafox al Exmo. Sr. D. Sebastián de Eslava, 19 de febrero de 1755.

42. Álvarez y Cañas, M. L.: Corregidores y Alcaldes Mayores..., Op. Cit., pp. 332-335. 
anterioridad del mismo modo, sosteniendo un constante desacuerdo con el fin privar de sus privilegios a los individuos relacionados con el cuerpo de Marina.

\section{INTROMISIÓN Y ABUSOS SOBRE LA JURISDICCIÓN DE MARINA DE CARTAGENA}

Palafox cosechó los primeros enfrentamientos con el intendente general de Marina, Francisco Barrero y Peláez ${ }^{43}$, cuando sólo había transcurrido poco más de un año en el mando de la plaza. El intendente defendía los derechos del fuero que representaba, relativos al mando administrativo y gubernativo de los arsenales, sus dependencias y empleados, frente a las irregularidades del gobernador. Las quejas elevadas a Julián de Arriaga, secretario de Marina, se remontaban a febrero de 1753 y concernían al trato despreciativo sobre el cuerpo de matriculados, que sufrió una incesante persecución por parte de Juan José de Palafox ${ }^{44}$.

Cualquier ocasión era propicia para detener a los individuos pertenecientes a ese fuero, interfiriendo en las causas privativas del juzgado de Marina que le correspondía en el caso de alguna infracción, según la interpretación argumentada por los interesados de las ordenanzas generales de la Armada y la normativa de intendentes. Las Ordenanzas de Marina, cuyas funciones y objetivos eran netamente militares, exigían que todos los miembros de los gremios dedicados al mar estuvieran matriculados para posibilitar su recluta como tripulación al servicio de la Real Armada ${ }^{45}$. En contraprestación, obtenían el derecho a realizar sus actividades vinculadas a la pesca y la navegación, no sólo en labores del mar sino también en las de tierra (constructores, aparejadores, especialistas...). También disfrutaban de una serie de exenciones sobre tributos personales y adquirían un fuero civil y criminal propio, sujetos a un ministro de Marina que sustanciaba sus causas a través del Consejo del Almirantazgo.

En el caso de Cartagena se produjeron fuertes altercados que enfrentaron a los responsables de las instituciones de su resguardo. La abundancia de casos dio lugar a varios expedientes donde se enumeraban y describían el modo de actuar del gobernador y sus subalternos en la práctica del encarcelamiento y el chantaje a los matriculados. En ocasiones se transgredía de forma directa el aforamiento de los mismos, y en otras, aunque también matriculados pero sólo sujetos parcialmente a los tribunales de Marina, se les extorsionaba con el propósito de percibir el importe de las sanciones que se les exigía ${ }^{46}$.

43. Consejero del rey, fue tesorero de la Armada de Barlovento, contador y fiscal de la Real Hacienda en Santiago de Cuba. Archivo General de Indias, Indiferente, Leg. 141, expediente $n^{\circ} 47$.

44. A.G.S., Guerra Moderna, Leg. 1.374: Francisco Barrero y Peláez a D. Julián de Arriaga, Cartagena, 24 de marzo de 1756.

45. Novísima Recopilación, Libro VI, Título VII: «Del servicio de la Marina; fuero y privilegios de sus matrículas», pp. 105-122.

46. Algunos de los matriculados eran asentistas de víveres y pertrechos, que sólo disfrutaban de fuero en lo respectivo a la provisión. 
En primer lugar, a partir de la reclamación de un tributo de dos reales de vellón a los marineros matriculados en calidad de validar su pasaporte, cuando una vez finalizados sus servicios en los navíos reales desembarcaban en Cartagena para restituirse a sus hogares ${ }^{47}$. El alguacil mayor de Marina relataba cómo a varios marineros catalanes y mallorquines que llegaron a la Puerta del Muelle con sus cajas y petates, a pesar de contar con sus pasaportes (expedidos por «sus jefes naturales»), se les detuvo por carecer de la firma del propio gobernador, ya que las guardias establecidas tenían órdenes de impedir su salida ${ }^{48}$. Del mismo modo, se aplicaba una tasa de derechos de embarque de 4 reales de vellón a los navíos llegados a Cartagena, e igual cantidad a los que provenían de la costa de la misma jurisdicción después de cargar carbón, leña o cualquier otro artículo para el abasto de la plaza, en contra de la real orden de 9 de febrero de 1751 que ya había prohibido dichos «abusos», y a pesar de las advertencias dirigidas al gobernador para que se contuviera en sus «excesos».

En segundo lugar, el despliegue de las rondas nocturnas por parte de funcionarios subordinados a Palafox se había convertido en una cruzada contra los matriculados, si bien también afectaba al resto de la población. En ocasiones, bajo el pretexto de que no llevaban la luz reglamentaria que debía iluminarles en su tránsito por la calle a partir de las 8 de la noche, se efectuaban implacables redadas con un elevado número de arrestos o, en su defecto, la inmediata extorsión que les libraría de la cárcel. Para ello no escatimaban en desmanes, como durante la detención del maestro mayor de toneleros, José Fuentes, a quien le arrebataron su farol de papel por llevarlo medio cubierto por la capa para que no lo apagara el viento. Fuentes expuso que se le había exigido el pago de 2 ducados de multa que debía entregar en casa de Palafox, y que al esgrimir su condición de matriculado el alguacil mayor, Javier de la Rosa, respondió: «a los matriculados es a quien nosotros buscamos». A pesar de sus súplicas y de las diligencias del Juzgado de Marina que reclamaba su liberación, junto a la de otros varios apresados el mismo día, el gobernador contestó que «no mandaría soltar a ningún matriculado, aunque hubiera mil presos ${ }^{49}$. Sin embargo, varios de los soldados del Regimiento de Caballería de Borbón que participaron en aquella ronda manifestaron su desaprobación ante el injusto encarcelamiento, por cuyo motivo el alguacil mayor los despidió y sustituyó por tropa del Regimiento de León para continuar la vigilancia a partir de las 10 de esa misma noche ${ }^{50}$.

Tampoco se libraban los vecinos que salían de visita a domicilios de sus amigos, tal y como le sucedió a Gabriel Sánchez, marinero y matriculado, a quien la noche del 15 de febrero, cuando abandonaba la casa de su compadre Andrés Estrella, acompañado de su mujer Rita Rodríguez y dos hijos menores, le prendió la ronda del alguacil

47. A.G.S., Guerra Moderna, Leg. 1.374: Manuel de la Riva, ministro de matrícula a D. Francisco Barrero Peláez, Cartagena 1 de marzo de 1756.

48. A.G.S., Guerra Moderna, Leg. 1.274: Cartagena, 2 de febrero de 1756.

49. A.G.S., Guerra Moderna, Leg. 1.274: Auto, 16 de febrero de 1756.

50. A.G.S., Guerra Moderna, Leg. 1.274: Expediente nº 3, Declaraciones de Juan Pelegrina, Tomás Jiménez, Antonio Galbez y Miguel Huertas, Cartagena, 28 de febrero de 1756. 
mayor. A pesar de los ruegos de su mujer y de reivindicar que era matriculado, le respondieron que «era un borrico de alquiler», insulto con el que solían denigrar la condición de todos los de su clase. Además le sacudieron violentos golpes y varios pinchazos con los fusiles produciéndole heridas. Esa misma noche, el alguacil mayor se vanagloriaba de haber detenido a diez matriculados, y que si el marinero hubiera pagado la multa de inmediato podría haberse librado de la prisión ${ }^{51}$.

El alguacil mayor, convertido en el cabecilla de todos los atropellos, tampoco hallaba ningún impedimento en invadir cualquier domicilio donde suponía que podía encontrar a algún matriculado. Así procedió la noche del domingo 29 de febrero cuando detuvo a tres calafates reunidos con el patrón de la barca que estaban construyendo, imponiéndoles una sanción de 30 reales a cada $u n o^{52}$.

La insolencia y el comportamiento pendenciero de Javier de la Rosa en sus procedimientos demostraban la seguridad que tenía en el respaldo del gobernador. Acompañado de varios subalternos se aprovechaba de la ley del miedo para amedrentar a cuantos eran testigos de sus extorsiones. Ese descaro llegaba al extremo de dejarse convidar en los domicilios donde irrumpía, con aguardiente, mistela y dulces, a la espera de recibir alguna retribución económica y mientras hacía alarde de su poder ${ }^{53}$. Las formas intimidatorias se mostraban en el uso de cualquier objeto que estuviera a su alcance para amenazar a sus víctimas. El protocolo de las rondas parecía haberse convertido en una noche de diversión para los protagonistas, hasta el extremo de acompañarse con una guitarra que también fue esgrimida en alguna ocasión como arma.

Las reclamaciones del intendente general de Marina y del aguacil mayor de la matrícula no obtenían ningún resultado, y se lamentaban de que era raro el día en que no se producían parecidos incidentes. Aunque reconocían que alguna temporada el número de detenciones había remitido, sabían que el acoso a los matriculados no había cesado, pues muchos afrontaban las cantidades de las multas impuestas antes de ingresar en la cárcel o de forma inmediata a su ingreso, renunciando a reclamar el amparo de su jurisdicción. Por otro lado, sospechaban que el propio Palafox había prohibido que se conociera el número de reos matriculados encerrados en el calabozo para eludir las reclamaciones de los responsables de Marina. De cualquier manera, para Barrero Peláez quedaba demostrado que el objetivo del alguacil mayor, siempre a las órdenes del gobernador, no era el de hacer cumplir las leyes sino el de extorsionar a los inculpados indiscriminadamente. Así fue el arresto sobre José Calderón, dependiente del arsenal, que fue encontrado a las 11 de la noche con una escopeta que llevaba para

51. A.G.S., Guerra Moderna, Leg. 1.274: Expediente nº 4, Declaración de Rita Rodríguez, mujer de Gabriel Sánchez, Cartagena, 18 de febrero de 1756.

52. A.G.S., Guerra Moderna, Leg. 1.274: Expediente nº 2, Memorial de José Ramón Blanca, Manuel Foto, y Francisco Jordán, Cartagena, 8 de marzo de 1756.

53. A.G.S., Guerra Moderna, Leg. 1.274: Expediente nº 4, Declaración de Rita Rodríguez, mujer de Gabriel Sánchez, Cartagena, 18 de febrero de 1756; Expediente n² 2, Memorial de José Ramón Blanca, Manuel Foto, y Francisco Jordán, Cartagena, 8 de marzo de 1756. 
defenderse de los ladrones. Amenazado con reconocer el arma como carabina prohibida, se avino a entregar 143 pesos de sanción para librarse de una pena de presidio ${ }^{54}$.

Barrero Peláez solicitaba con insistencia que se pusiera fin a los desprecios que sufría el fuero de los matriculados ${ }^{55}$, pues se corría el riesgo de no poder contar con la marinería y el cuerpo de la maestranza, necesarios al servicio real, ya que esos individuos eran los que se encontraban más perseguidos que el resto de los vecinos, impositiva y judicialmente, al tener que afrontar dobles responsabilidades relativas a las justicias ordinaria y a la de marina. Del mismo modo recordaba el artículo 146, que encomendaba a los ministros provinciales y subdelegados de Marina «la policía de los matriculados», puesto que las Ordenanzas eran el instrumento normativo que velaba sobre la justicia que se debía impartir de manera privativa.

Barrero Peláez también solicitó la colaboración del Alcalde mayor, que en su función de asesor debía servir de guía en los asuntos propios del corregidor para posteriormente juzgarlos de común acuerdo. Según las noticias recabadas por obra de Bermúdez de Castro, no sólo se cometían excesos contra los matriculados de Marina, sino también sobre el resto del vecindario, aún más expuesto a la tiranía de los acólitos del gobernador y sin la posibilidad de encontrar respaldo en otro fuero. El letrado denunciaba el manejo de la justicia por parte de quien no estaba preparado profesionalmente para ello e ignoraba de forma notoria las leyes. El proceder del alguacil mayor Javier de la Rosa también era irregular, pues aunque había sido advertido por el alcalde mayor para que le asistiese en las rondas de la plaza, siempre se excusó con el pretexto de que patrullaba por separado por encargo del gobernador, teniendo a su exclusiva disposición un elevado número de empleados para ese ejercicio, frente a desasistencia de Bermúdez de Castro. El desafuero llegaba al extremo de que el capitán de llaves rondaba acompañado de un escribano y varios oficiales del juzgado, procediendo a realizar sumarias, inventarios y cuantas diligencias precisaba por su cuenta. Así se pudo deducir de la salida de más de 20 presos tras la visita a la cárcel en la Navidad de 1755, tras padecer penas de meses y años de prisión, algunos sin tener causa judicial escrita ${ }^{56}$.

Las dificultades del reparto profesional de competencias entre los corregidores y los alcaldes mayores fueron más graves en el caso de los gobiernos militares, puesto que los encargados del mando añadían a sus funciones castrenses las políticas, hecho que les investía de un poder casi soberano en su circunscripción. La tendencia de los

54. A.G.S., Guerra Moderna, Leg. 1.274: Manuel de la Riva a D. Francisco Barrero Peláez, Cartagena, 16 de marzo de 1756; y Francisco Barrero y Peláez a D. Julián de Arriaga, Cartagena, 24 de marzo de 1756.

55. Martínez Shaw, C. y Fernández Díaz, R: «La gente de Mar en la Cataluña del siglo XVIII», en Primer Congrès d'Historia Moderna de Catalunya, Vol. 1, Universidad de Barcelona, Barcelona, 1984, pp. 553-568; Burgos Madroñero, M: «La matrícula de Mar en la provincia de Marina de Algeciras, siglos XVIII y XIX», en Almoraima: Revista de Estudios Campogibraltareños, n 5, 1991, pp. 243-256; VÁzQuez, J. M.: «Los privilegios de la matrícula de Mar y su cuestionamiento práctico. La dureza del real servicio en la Armada en el siglo XVIII», en Obradoiro de Historia Moderna, nº 6, (1997), pp. 107-130.

56. A.G.S., Guerra Moderna, Leg. 1.374: Francisco Bermúdez de Castro a D. Francisco Barrero Pelaéz, Cartagena, 13 de marzo de 1756. 
gobernadores político-militares a inmiscuirse en las funciones conferidas a los alcaldes mayores se extendió también a las competencias judiciales. En la interpretación interesada de la normativa, los corregidores intentaron en varias ocasiones privar a los letrados de sus funciones e incitar con facilidad al enfrentamiento.

\section{AVERIGUACIÓN DE LOS CARGOS DELICTIVOS COMETIDOS EN LA ADMINISTRACIÓN DE JUAN JOSÉ DE PALAFOX}

Las circunstancias políticas de Cartagena no escapaban al conocimiento público, y a través de anónimos también salía a relucir la impopularidad de Juan José de Palafox. Redactados por la misma persona en distintas fechas, identificado como ministro de Dios, en ocasiones bajo la firma de «su criado, servidor y capellán», llegaron a manos del gobernador del Consejo, del secretario de Estado y del secretario del Despacho Universal de Guerra, varias cartas anónimas cuyo contenido era muy similar. En ellas se denunciaba el padecimiento de los vecinos en un listado de agravios que se podría resumir en las siguientes cuestiones: las numerosas detenciones bajo la acusación de no portar la luz nocturna; la incautación a los dueños de las llaves de las casas en disposición de alquiler, junto a la prohibición a los escribanos de formalizar contratos de venta sin una licencia previa del gobernador ${ }^{57}$; la utilización de un cepo y cárcel en el domicilio de Juan José de Palafox, para obtener de primera mano los beneficios de carcelaje; la apropiación de las tutelas sobre las herencias legítimas de viudas y huérfanos, a través de un testaferro; la exigencia de 2 reales a todas las embarcaciones que entraban o salían del puerto a cuenta de una licencia dispensada por el gobernador ${ }^{58}$; la malversación en las cuentas del Almodí, el cobro de impuestos en la entrada de alimentos, y la prohibición del acarreo de harina; el contrabando de seda desde la villa de Algezares, siendo el gobernador el principal comprador y quien enviaba los barcos para transferir el género a navíos franceses, desde un punto de la costa convenientemente desguarnecido de las rondas ${ }^{59}$; y el abandono de los cadáveres en las puertas de los domicilios hasta no obtener un tributo para su traslado a una sepultura.

Todos los cargos atribuidos a Palafox se referían a su búsqueda de enriquecimiento ilícito ${ }^{60}$. Prueba de ello era la creciente y rápida posesión de bienes acumulados por

57. El negocio consistía en adjudicar las casas a aquellos que le obsequiaran con una gratificación a cambio de facilitarles el domicilio. A.G.S., Guerra Moderna, Leg. 1.374: Al Exmo. Sr. D. Ricardo Wall, Cartagena, 11 de febrero de 1756.

58. «ni el vecino, por diversión aunque tenga barco propio, ni el pobre que viene de cumplir destierro en Orán, ni el pasajero más mendigo» se libraban de la reclamación. A.G.S., Guerra Moderna, Leg. 1.374: Cartagena, 4 de febrero de 1756.

59. A.G.S., Guerra Moderna, Leg. 1.374: Al Exmo. Sr. D. Sebastián de Eslava, Cartagena, 14 de febrero de 1756.

60. Sobre diversos casos delictivos protagonizados por las élites de gobierno: GimÉNEz LóPEz, E. y PrADELLS NADAL, J.: «Conflictos entre la intendencia y la capitanía general de Valencia durante el reinado de Felipe V. Las denuncias de corrupción», SHHM, VII, 1989, pp. 591-599; Franch BENAVENT, R.: «Las oportunidades de enriquecimiento ilícito generadas por el ejercicio de la intendencia más tentadora de España: 
el gobernador en propiedades que alcanzaban un valor de 50.000 pesos. Para conseguirlo había contado con la complicidad y la asistencia del alguacil mayor, -Javier de la Rosa-, el guarda llaves, -Juan de Castro-, y con los escribanos José Ponce y Pascual Piqueras, que en la aplicación indebida de labores de policía y de justicia habían ideado toda clase de argucias para robar al pueblo, según se podía comprobar por el número de inculpados registrado en el libro de entrada de la cárcel, con distintos desenlaces según sus posibilidades económicas ${ }^{61}$.

Los anónimos también censuraban la conducta del gobernador en relación al prestigio y la honradez de su familia. Por un lado, recordaban a Juan de Palafox y Mendoza («tan uno en el nombre como distinto en virtudes»), obispo de Puebla de los Ángeles (Nueva España) y de Osma, que también desempeñó circunstancialmente los cargos de consejero de Indias, virrey y Capitán General de Nueva España, cuya fama de santidad favoreció que desde 1666 se encontrara en proceso de beatificación ${ }^{62}$. Por otro, la sólida posición de su hermana por parte de madre, Rosa María Fernández de Castro y Centurión, marquesa de Aytona, camarera de la reina, hacía temer que las influencias de la Corte evitaran la merecida sanción a los desmanes ${ }^{63}$.

En definitiva, para librarse de las deplorables consecuencias del proceder de Palafox el anónimo informador recomendaba su traslado a otro empleo, aunque fuera de mayor categoría, pero que careciera de facultades políticas y de administración de justicia. Además, remitía a la confirmación de estos hechos por parte del comandante general del Departamento de Cartagena ${ }^{64}$.

Para la averiguación de los pormenores, ante la cantidad y gravedad de cargos que posiblemente fueran imputables como delitos, Sebastián de Eslava, secretario del Despacho de Guerra, solicitó un informe de una persona allegada al gobernador, que

La pesquisa realizada al marqués de Avilés como intendente de Velencia en 1762», Estudis, 28, 2002, pp. 263-285.

61. A juicio del informador anónimo: «su inocencia ha sido el tener o no dinero, pues habiéndolo el delito es inocencia, y no habiéndolo, la inocencia es delito». A.G.S., Guerra Moderna, Leg. 1.374: Cartagena, 4 de febrero de 1756.

62. Había sido hijo natural de Jaime Palafox, II marqués de Ariza, y su proceso de beatificación se prolongó hasta el año 2011, en que fue concedido por Benedicto XVI. Soladana, V.: El venerable don Juan de Palafox y Mendoza Obispo de Osma (1654-1659), Obra Cultural de la Caja de Ahorros y Préstamos de la Provincia de Soria, Soria, 1982.

63. También fue camarera de la reina María Amalia de Sajonia (1759-1760). Nacida en 1691, era hija del primer matrimonio de Francisca de Paula Mejía y Centurión. Mercurio histórico político, pp. 251-252; Soler Salcedo, J. M.: Nobleza española: grandeza inmemorial, 1520, Visión Libros, 2008, pp. 271272.

64. A.G.S., Guerra Moderna, Leg. 1.374: Al Exmo. Sr. D. Sebastián de Eslava, Cartagena, 14 de febrero de 1756 . 
con imparcialidad detallara la credibilidad de cuantas denuncias le acusaban de despotismo, cohecho, extorsión y malversación ${ }^{65}$.

El testimonio firmado en marzo de 1756 por José Deona, oficial del regimiento de Dragones destinado en Cartagena, exponía los detalles del comportamiento del gobernador. A pesar de reconocer la capacidad de trabajo de Palafox, no podía soslayar su carácter ambicioso, acaparador de cuantas causas económicas, políticas y judiciales se presentaban en su tribunal, desposeyendo al alcalde mayor, a quien sólo concedía su participación en procesos criminales de poca entidad económica y profesional.

En colaboración con Palafox se encontraban los cómplices ya señalados, a quienes Deona añadía los escribanos Francisco Poveda y José Minaya. La red de corruptela se mostraba públicamente en el trato frecuente y familiar que les prestaba, de modo que el gobernador se convertía en sospechoso de participar en las extorsiones.

La ordenanza sobre la obligación de transitar con luz en horas nocturnas era legítima; sin embargo, su cumplimiento era ejercido de forma fraudulenta por el alguacil mayor y sus «satélites», que por no tener un salario fijo empleaban estratagemas para recaudar sin rigor a cuantos incautos encontraban. De hecho, Javier de la Rosa, «de un estado miserable», había acumulado una fortuna en los dos años que llevaba empleado como alguacil mayor.

Respecto al control del mercado inmobiliario, era cierta la prohibición dictada por el gobernador sobre las escrituras de venta de casas sin su consentimiento, así como la incautación de llaves de las casas que quedaban libres de inquilinos, y sólo respetaba las de los regidores. Si bien el beneficiado de esta componenda era el guarda-llaves Juan de Castro, cuyo hijo también sacaba provecho de los arrestados en el cepo y cárcel del domicilio del gobernador, propiciando su liberación mediante coima.

En cuanto al secuestro de tutelas sobre herencias, era conocido el caso de cuatro huérfanos de holgada posición económica a los que el escribano Francisco Poveda perjudicó en sus derechos legales, para conseguir la administración fraudulenta de sus bienes con el consiguiente menoscabo de su patrimonio.

Sobre la acusación del corregidor en el contrabando de seda, aunque sin realizar una pesquisa resultaba imposible determinar el grado de implicación, sí era sospechosa la frecuencia de extracciones del género en grandes cantidades. Del mismo modo, era constante que las embarcaciones del resguardo aparentaran diligencias en persecución de los contrabandistas y se dirigieran a patrullar en la zona contraria a donde se realizaban los desembarcos ilícitos, mostrando las alianzas entre el gobernador y el comandante de rondas Alonso Angulo con los traficantes de Algezares.

La carga impositiva sobre los pasajeros entre Cartagena y Oran, y sobre el resto de embarcaciones era también constatable.

65. Los amplios cometidos de Eslava le obligaban a supervisar las competencias y actuaciones militares de toda índole, incluidos los de la administración territorial. Escudero LóPEz, J.A.: Los orígenes del Consejo de Ministros en España: La Junta Suprema de estado, Editora Nacional, 1979, Madrid, Tomo I, p. 231. 
Para el manejo del Almudí se nombraba con anterioridad a seis comisarios, que habían sido reducidos a tres, entre los que se hallaba el regidor Francisco Rosique, a quién el gobernador le había conseguido las pruebas para obtener el hábito de Santiago ${ }^{66}$. Al parecer, la administración del pósito fue objeto de un largo debate entre los capitulares del ayuntamiento, que incluso se excusaron de concurrir a las juntas para evitar la ira del gobernador. Como consecuencia, el suministro del pan se encontraba estancado, pues no se permitía la adquisición del trigo o la harina que llegaba al puerto, obligando a comprar sólo la del Almudí a un precio elevado, y sin que nadie tuviera conocimiento del paradero de las inmediatas ganancias.

También era visible el enriquecimiento del gobernador en las casas que disfrutaba, tanto para vivir como para alquilar, dando mal ejemplo en los elevados importes de renta que exigía, si bien la totalidad de sus propiedades ascendía a un valor de 30.000 pesos.

Para concluir, José Deona recomendaba el traslado de Juan de Castro a otra plaza con el mismo empleo; que se privara a Javier de la Rosa de la vara de alguacil mayor; que se suspendieran de ejercicio por dos años a los escribanos, y el relevo de Alonso Angulo. Con estas medidas confiaba que el gobernador suprimiría las estafas, al tiempo que coincidía en que sería conveniente la promoción de Palafox a otro empleo de mayor fuste pero sin mando político ${ }^{67}$.

Aunque los perjudicados por el proceder del gobernador y de sus acólitos eran de muy variado origen, Deona no había aludido a la especial inquina que recaía sobre los matriculados, por lo que el alguacil de matrícula en un recurso dirigido al intendente Barrero Peláez se vio obligado a denunciar la gravedad de su situación:

«El cuerpo de matriculados es el principal objeto de la indignación, y a quien con más esmero persiguen, no contentándose con quitarles el dinero con pretextos [...] sino que de más a más los mofan, oprobian y ultrajan de obra y de palabra, con la depravada intención de difundir en todo el género humano aborrecimiento y horror a la matrícula, desacatando al mismo tiempo la jurisdicción de Marina, y su jefes; y lo que más es menospreciando las Reales Ordenanzas $\rangle^{68}$.

Tanto por su elevado número en la ciudad de Cartagena, como por la seguridad de que se hallaban empleados al servicio de las amplias necesidades del Departamento de Marina, y en distinta medida obtenían un salario, se habían convertido en un objetivo seguro para obtener a su costa provecho económico.

En definitiva, la desmesurada ambición de Juan José de Palafox se encontraba en el fondo de todos los fraudes económicos y desmanes políticos que caracterizaron

66. Por 4.000 pesos y otros regalos «además de una cuadrilla de plebeyos y soeces regidores, y otros a los que ha declarado por sí y ante sí hidalgos, enmendando los tales cuales padrones [...] y todas estas justificaciones por dinero».

67. A.G.S., Guerra Moderna, Leg. 1.374: D. José Deona al Exmo. Sr. D. Sebastián de Eslava, Cartagena, 10 de marzo de 1756.

68. A.G.S., Guerra Moderna, Leg. 1.374: Manuel de la Riva al Sr. D. Francisco Barrero Peláez, Cartagena, 27 de marzo de 1756. 
su gestión. No obstante, tampoco era desdeñable una motivación vengativa hacia los responsables de Marina, cuya enemistad marcó todo el periodo de gobierno.

\section{DESENLACE DEL GOBIERNO Y DIMISIÓN SECRETA DE JUAN JOSÉ DE PALAFOX}

La difusión en la Corte de los recursos contra el gobernador dio lugar a la esperada censura. Así, el auditor de Guerra, a petición del secretario de Marina, recriminaba los abusos de Palafox y le conminaba a que se contuviera en el uso de su jurisdicción ${ }^{69}$. El 27 de marzo de 1756 el gobierno central dio aviso al capitán general de Valencia de una orden que reclamaba la presencia del gobernador de Cartagena, al mismo tiempo que se le hacía saber al interesado la necesidad de su marcha aunque sin especificar el motivo $^{70}$.

A principios de mayo Ricardo Wall comunicaba a Sebastián Eslava la necesaria dimisión secreta de Palafox como medida más favorable y prudente, en consideración a los méritos de su familia y para evitar el desprestigio en su honor. El procedimiento contemplaba su regreso a Cartagena para recoger a su familia, donde Palafox debía dar a entender que había solicitado una licencia para su retiro. Mientras tanto podría mantenerse con el título de gobernador evitando entrometerse en materias o negocios ajenos a su cargo. Eslava propondría al rey otro empleo para Palafox, así como el sustituto correspondiente al gobierno de la plaza de Cartagena ${ }^{71}$. También fue el responsable de comunicar a Palafox la exigencia sobre su dimisión secreta, con la advertencia de su ejercicio únicamente como gobernador militar en el plazo de un mes ${ }^{72}$. Además, la dimisión había ser de palabra, nunca por escrito, en consideración al demérito que podría acarrear a su familia ${ }^{73}$. Sin embargo, Eslava opinaba que la supresión del mando político podía alertar a los vecinos de las circunstancias sancionadoras recaídas sobre el gobernador, con lo que la intención de confidencialidad se perdía ${ }^{74}$, por lo que finalmente se autorizó a Palafox que continuara con ambas jurisdicciones hasta su relevo ${ }^{75}$.

El gobernador de Cartagena formuló su renuncia el 24 de mayo expresando problemas de salud, con la petición de que se le concediera un sueldo para su retiro en

69. A.G.S., Guerra Moderna, Leg. 1.374: Julián de Arriaga a D. Pedro Salavador de Muro, Buen Retiro, 29 de marzo de 1756.

70. A.G.S., Guerra Moderna, Leg. 1.374: A Caylus, Madrid, 27 de marzo de 1756; A Palafox, Madrid, 27 de marzo de 1756; Juan José de Palafox al Exmo. Sr. D. Sebastián de Eslava, Cartagena, 31 de marzo de 1756 .

71. A.G.S., Guerra Moderna, Leg. 1.374: Ricardo Wall a Sebastián Eslava, Aranjuez, 3 de mayo de 1756.

72. A.G.S., Guerra Moderna, Leg. 1.374: Sebastián Eslava al Sr. D. Juan José de Palafox, Buen Retiro, 7 de mayo de 1756.

73. A.G.S., Guerra Moderna, Leg. 1.374: Ricardo Wall a Sebastián Eslava, Aranjuez, 19 de mayo de 1756.

74. A.G.S., Guerra Moderna, Leg. 1.372: Sebastián Eslava al Exmo. Sr. D. Ricardo Wall, 21 de mayo de 1756.

75. A.G.S., Guerra Moderna, Leg. 1.374: Ricardo Wall al Sr. D. Sebastián Eslava, Aranjuez, 23 de mayo de 1756 . 
Cataluña o Valencia ${ }^{76}$. En el mismo contexto se habían producido las reclamaciones de su hermano el marqués de Ariza ${ }^{77}$, solicitando al rey un destino acorde a su categoría profesional, en el que no teniendo jurisdicción política se evitara la desconfianza de su posible reincidencia ${ }^{78}$.

El 18 de junio de 1756 Eslava propuso que se le confiriera el gobierno militar de Ciudad Rodrigo, en conformidad a la petición del marqués de Ariza, nombramiento que se hizo efectivo al día siguiente; no obstante, tal vez encontrando la ocasión para librarse de tan incómodo personaje, también quiso subrayar que Palafox en ningún momento le había expresado su ánimo de continuar ejerciendo el gobierno territorial ${ }^{79}$. El título del nuevo empleo se expidió el 26 de julio, con igual salario de 250 escudos obtenido hasta entonces ${ }^{80}$.

Lo cierto es que el regreso de Juan José de Palafox a Cartagena fue contraproducente, pues lejos de mantener la discreción necesaria expresó en público que en la Corte no le querían admitir su renuncia y que cualquier crítica a su gestión sólo procedía de la calumnia. El gobernador, sin enmienda, se había apresurado a recaudar en esos días dinero a costa de detenciones, tramitaciones judiciales, contrabando, multas y fraudes. Sus maniobras habían provocado la marcha de varios vecinos, así como la ruina de algunos comerciantes. Además, la soberbia del militar iba aún más lejos, pues sin la más leve señal de disponer su salida aseguraba que aunque ya se encontraba nombrado para el gobierno de Ciudad Rodrigo dudaba de su marcha, aventurando que Eslava podía caer en desgracia dejando así sin efecto el relevo ${ }^{81}$.

En defensa del honor de Palafox intervino también su esposa, Josefa Castellet, que ensalzaba la carrera de su marido desde el año 1724 y clamaba contra la injusticia de las acusaciones. Respecto a sus circunstancias económicas aclaraba que tres vecinos le prestaron 9.000 pesos para comprar una casa y arreglar otras tres pequeñas en el terreno donde se hallaba su domicilio principal, porque le impidieron alquilarla cuando en ella vivía un criado favorecido por los asentistas de Marina. Por otro lado, Palafox contaba con 1.500 ducados de rentas que le daba su hermano el marqués de Ariza, su encomienda, su sueldo y las cantidades que anualmente le entregaba su hermana la marquesa de Aytona. Su hijo Juan recibía 50 doblones de pensión, más la liquidación

76. A.G.S., Guerra Moderna, Leg. 1.372: Juan José de Palafox al Exmo. Sr. D. Sebastián de Eslava, Madrid, 24 de mayo de 1756.

77. Joaquín Antonio Palafox y Rebolledo, caballerizo mayor del Príncipe de Asturias, conde de Santa Eufemia y La Monclova. Cádenas y Vicent, V.: Extracto de los expedientes de la Orden de Carlos III (1771-1847), Tomo IX, Instituto Salazar y Castro (CSIC), Hidalguía, Madrid, 1986, pp. 205-206.

78. A.G.S., Guerra Moderna, Leg. 1.374: Ricardo Wall a Sebastián Eslava, Aranjuez, 16 de junio de 1756.

79. A.G.S., Guerra Moderna, Leg. 1.372: Sebastián Eslava al Exmo. Sr. D. Ricardo Wall, Buen Retiro, 18 de junio de 1756; y Ricardo Wall a D. Sebastián Eslava, Aranjuez, 19 de junio de 1756.

80. A.G.S., Guerra Moderna, Leg. 1.374: Sebastián de Eslava al Sr. D. Cristobal de Taboada, 26 de julio de 1756.

81. A.G.S., Guerra Moderna, Leg. 1.372: Su servidor y capellán al Exmo. Sr. D. Sebastián de Eslava, 13 de julio de 1756; y Leg. 1.374: Su servidor y capellán al Exmo. Sr. D. Sebastián de Eslava, Cartagena, 15 de agosto de 1756 . 
del beneficio de su tía, condesa de Ricla ${ }^{82}$. Sin embargo, según Josefa Castellet el intendente de Marina y otros cercanos a sus intereses sí habían derrochado en propiedades y lujos. Tampoco escapaba a sus críticas el alcalde mayor, a quien consideraba «impolítico y majadero» ${ }^{83}$.

Antes de su partida, Palafox tampoco olvidó su desprecio por el alcalde mayor y aprovechó para denostar su proceder profesional. Le acusaba de desentenderse de sus responsabilidades de gobierno permitiendo escándalos, robos, altercados y violencias con lesiones. Por ello solicitaba mantener el mando hasta entregarlo a su sucesor (dilatando así su estancia en Cartagena, tal y como confirmaban los anónimos), pues no le parecía decoroso abandonarlo ante esos desaciertos. Sin embargo, contra este propósito Bermúdez de Castro había obtenido un despacho del Consejo para servir el mando político, que derogaba el que tenía el teniente de rey en los casos de ausencia del gobernador propietario ${ }^{84}$.

La polémica se solventó con una escueta orden en la que se dejaba a su arbitrio el tiempo de su salida de Cartagena, pero con la advertencia de depositar cada jurisdicción en manos de los responsables a quienes competía la administración de lo político, el alcalde mayor, y lo militar, el teniente de rey $^{85}$, si bien quedaron sin resolver los problemas de fondo que afectaban al gobierno de la plaza.

Finalmente, se nombró a su sucesor en octubre de 1756, cargo que recayó en Ambrosio Funes de Villalpando, conde de Ricla, emparentado con Palafox por su matrimonio con María Micaela Gómez de los Cobos Palafox, hija de su hermana ${ }^{86}$. En cuanto a Juan José de Palafox, consiguió tras su ejercicio en Ciudad Rodrigo el ascenso a teniente general.

La normativa instaurada en Cartagena sometió a la administración a las prioridades castrenses y, en este caso, al talante particular de Juan José de Palafox. Salvo el cese en el empleo, de una forma secreta, no se produjo ningún castigo adecuado a las infracciones cometidas. La pertenencia a una casta social tan cercana a la corte mereció un trato indulgente, que fue muy usual en circunstancias parecidas ocurridas en otras circunscripciones. Esta tolerancia dejaba en la indefensión a los perjudicados con el manejo arbitrario del gobernador, al tiempo que vaciaba de contenido las leyes rectoras

82. Se trataba de Juliana Paulina de Palafox y Centurión, hermana de su padre, casada con Miguel de los Cobos Gómez Manrique, Grande de España, XII conde de Ribadavia, VI marqués de Camarasa y IV conde de Ricla. Rivarola y Pineda, J. F.: Monarquía española: Blasón de su nobleza, Volumen 2, Imprenta de Alfonso Mora, Madrid, 1736, p. 198.

https://www.google.es/search?tbm=bks\&hl=es\&q=Monarquia+Espa $\% \mathrm{C} 3 \% \mathrm{~B} 1 \mathrm{ola} \% 2 \mathrm{C}+\mathrm{Blason}+\mathrm{de}+\mathrm{su}$ +Nobleza

83. A.G.S., Guerra Moderna, Leg. 1.374: Josefa de Palafox y Castellet al Exmo. Sr. D. Sebastián Eslava, Cartagena, 4 de agosto de 1756.

84. A.G.S., Guerra Moderna, Leg. 1.374: Juan José de Palafox al Exmo. Sr. D. Juan de Eslava, Cartagena, 18 de agosto de 1756

85. A.G.S., Guerra Moderna, Leg. 1.374: Juan de Eslava a D. Juan José de Palafox, Madrid, 4 de septiembre de 1756.

86. A.G.S., Guerra Moderna, Leg. 1.372: 9 de octubre de 1756. 
de la buena administración de justicia. El problema se enquistaba en la impunidad de las actividades delictivas, con el menoscabo para los intereses reales y la administración que debía garantizar el sistema de gobierno.

Las interpretaciones sesgadas de la legislación o la ignorancia de la misma, fomentando y consintiendo abusos competenciales, oscuros manejos administrativos, extorsiones y luchas de poder, conformaron en conjunto un grave lastre para la administración territorial, constituyendo una inconveniente herencia que influiría en los gobiernos posteriores y a costa del necesario control de la proyección ultramarina y estratégica de Cartagena. 